\title{
Erratum to: Isosteric heat of hydrogen adsorption on MOFs: comparison between adsorption calorimetry, sorption isosteric method, and analytical models
}

\author{
A. F. Kloutse ${ }^{1} \cdot$ R. Zacharia ${ }^{1}\left(\mathbb{D} \cdot\right.$ D. Cossement ${ }^{1} \cdot$ R. Chahine $^{1} \cdot$ R. Balderas-Xicohténcatl ${ }^{2} \cdot$ \\ H. $\mathrm{Oh}^{2} \cdot$ B. Streppel ${ }^{2} \cdot$ M. Schlichtenmayer ${ }^{2} \cdot$ M. Hirscher ${ }^{2}$
}

Published online: 1 June 2016

(C) Springer-Verlag Berlin Heidelberg 2016

Erratum to: Appl. Phys. A (2015) 121:1417-1424

DOI 10.1007/s00339-015-9484-6

Due to a technical issue in production the article "Isosteric heat of hydrogen adsorption on MOFs: comparison between adsorption calorimetry, sorption isosteric method, and analytical models" by A. F. Kloutse, R. Zacharia, D. Cossement, R. Chahine, R. Balderas-Xicohténcatl, H. Oh, B. Streppel, M. Schlichtenmayer, M. Hirscher, published December 2015, Volume 121, Issue 4, pp 1417-1424 had not been published as part of the topical collection "Hydrogen-based Energy Storage". The publisher apologizes for this and for any inconvenience caused.

The online version of the original article can be found under doi:10.1007/s00339-015-9484-6.

R. Zacharia

renju.zacharia@uqtr.ca

1 Institut de recherche sur l'hydrogène, Université du Québec à

Trois-Rivières, Trois-Rivières, QC G9A 5H7, Canada

2 Max-Planck Institute for Intelligent Systems,

Heisenbergstrasse 3, 70569 Stuttgart, Germany 